\title{
MC Simulates the Detection Efficiency of Different Sizes of BaClBr(Eu)
}

\author{
Junxin Zhang, Yifan Jin, Xu Zhao, Qiushi Liu, Ruiyang Xu, Yu Liu \\ Applied Nuclear Technology in Geosciences Key Laboratory of Sichuan Province, Chengdu University of Technology, Chengdu, \\ China \\ Email: zhangjunxin_1314@163.com
}

How to cite this paper: Zhang, J.X., Jin, Y.F., Zhao, X., Liu, Q.S., Xu, R.Y. and Liu, Y. (2020) MC Simulates the Detection Efficiency of Different Sizes of $\mathrm{BaClBr}(\mathrm{Eu})$. Open Access Library Journal, 7: e6655. https://doi.org/10.4236/oalib.1106655

Received: July 24, 2020

Accepted: August 17, 2020

Published: August 20, 2020

Copyright $\odot 2020$ by author(s) and Open Access Library Inc.

This work is licensed under the Creative Commons Attribution International License (CC BY 4.0).

http://creativecommons.org/licenses/by/4.0/

\section{(c) (i) Open Access}

\begin{abstract}
The performance of a new $\mathrm{BaClBr}(\mathrm{Eu})$ scintillator discovered in recent years was studied. The photon yield and detection efficiency of different sizes of the theoretical model of the $\mathrm{BaClBr}(\mathrm{Eu})$ detector were calculated by the MCNP program, and compared with the traditional $\mathrm{NaCl}(\mathrm{Tl})$ detector. Studies have found that the detection efficiency of the scintillator detector increases as the size of the scintillator increases. When the $\gamma$-ray energy is $662 \mathrm{KeV}$, the photon yield of the $\mathrm{BaClBr}(\mathrm{Eu})$ detector is lower than that of the $\mathrm{NaCl}(\mathrm{Tl})$ detector, and the light yield difference is $6.21 \%-3.15 \%$. The detection efficiency of $\mathrm{BaClBr}(\mathrm{Eu})$ scintillator is higher than that of $\mathrm{NaCl}(\mathrm{Tl})$ scintillator, and the relative efficiency is $11.7 \%-22.52 \%$. Simulating the effect of different ray energy on the photon yield and detection efficiency of the scintillator under the same crystal size, it is found that the photon yield of the $\mathrm{BaClBr}(\mathrm{Eu})$ scintillator is between the $\mathrm{NaCl}(\mathrm{Tl})$ and $\mathrm{CsI}(\mathrm{Tl})$ scintillator detectors. The detection efficiency of low-energy rays is close to that of $\mathrm{NaCl}(\mathrm{Tl})$, and the detection efficiency of high-energy rays is much higher than that of $\mathrm{NaCl}(\mathrm{Tl})$. The detection efficiency of the high and low ray energy range is close to that of the $\mathrm{CsI}(\mathrm{Tl})$ detector.
\end{abstract}

\section{Subject Areas}

Nuclear Physics

\section{Keywords}

Mento Carlo Method, Detection Efficiency, $\mathrm{BaClBr}(\mathrm{Eu})$ Crystal, $\gamma$-Ray

\section{Introduction}

With the advancement of photomultiplier tubes and other microscopic detection 
devices and technologies, scintillator detectors have been rapidly developed and widely used. They are usually used in nuclear physics and high energy physics, medicine, diffraction, nondestructive testing, national security and geological exploration and other fields [1] [2]. Since the discovery of scintillation crystal $\mathrm{NaI}(\mathrm{Tl})$ in 1948, scientists have been looking for scintillation crystal materials with high atomic number, high density, high transmittance, physical and chemical properties and excellent scintillation properties. In recent years, a new type of alkaline earth metal halide $\mathrm{BaClBr}(\mathrm{Eu})$ crystal has been discovered internationally [3] [4] [5]. It has the characteristics of high density, high atomic number, high light output and high energy resolution, and has good application prospects.

In this paper, the Monte Carlo method is used to simulate and calculate the effects of different sizes and different ray energies on the luminescence yield and source peak efficiency of $\mathrm{BaClBr}(\mathrm{Eu})$ crystals, and compare the performance with the scintillation crystal $\mathrm{NaCl}(\mathrm{Tl})$. On this basis, the influence of the size of the scintillator on the performance of the scintillator is discussed. The simulation results can provide reference for the selection of scintillator size and the manufacture of scintillator detector.

\section{Mcnp Modeling}

Monte Carlo method is a calculation method based on the simulation of photon and electron coupling transport problem [6]. MCNP (Monte Carlo Neutron and Photo Transport Code) program is based on the Monte Carlo method to deal with particle transport, which can effectively solve the photon and electron coupling transport process. It simulates the interaction of photons and electrons.

The geometric model of the $\mathrm{BaClBr}(\mathrm{Eu})$ detector is shown in Figure 1. Including two parts: ray source and detector. The ray source is a point source, which emits $\gamma$-rays with adjustable energy, $20 \mathrm{~cm}$ away from the detector. The detector includes a scintillator, a reflective layer, a protective layer and a light guide. The geometry of the scintillator is a cylinder with adjustable size. The reflective layer material MgO: $0.05 \mathrm{~cm}$. The protective layer material Al: $0.2 \mathrm{~cm}$. The light guide material $\mathrm{SiO}_{2}: 0.2 \mathrm{~cm}$. The number of gamma photons: $10^{7}$. F1 counter card records the output light integral flow through the contact surface of the scintillator and the light guide. The F8 counter card records the pulse height

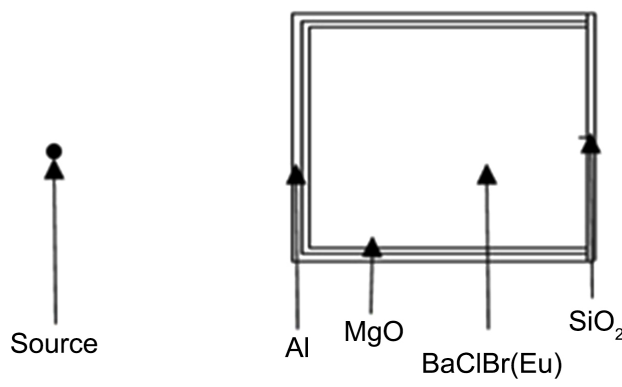

Figure 1. $\mathrm{BaClBr}(\mathrm{Eu})$ detector geometry model. 
energy spectrum distribution of the $\gamma$-ray in the scintillator. The E8 card calculates the detection efficiency of the scintillator [7].

\section{Photon Yield and Detection Efficiency}

Photon yield and detection efficiency are two important indicators to measure the performance of scintillator detectors [8]. Photon yield represents the ability of a scintillator to convert absorbed ray energy into light pulses [2]. The higher the photon yield of the scintillator, the more photons converge to the optoelectronic device, and the higher the energy resolution, and the better the performance. The photon yield is defined as the ratio of the number of photons generated during the scintillation process to the energy lost by the particles in the scintillator, and the expression is:

$$
Y_{p h}=n_{p h} / \Delta E
$$

In the formula: $Y_{p h}$ is the photon yield, in $\mathrm{MeV}^{-1} \cdot n_{p h}$ is the number of photons produced in the scintillator. $\Delta E$ is the energy lost by the particle in the scintillator, in $\mathrm{MeV}$.

There are many ways to record the detection efficiency, which can generally be divided into source detection efficiency and source peak detection efficiency. In order to eliminate the influence of counting and noise interference caused by the scattering of surrounding objects and other factors [9], source peak detection efficiency can be selected to describe the performance of the detection crystal itself. The detection efficiency of the source peak detection efficiency is defined as the ratio of the count of all-energy peaks in the $\gamma$ energy spectrum to the number of $\gamma$ photons emitted by the radioactive source. The expression is:

$$
\varepsilon_{s p}=N_{i} / N
$$

In the formula: $\varepsilon_{s p}$ is the source peak detection efficiency. $N_{i}$ is the count within the all-energy peak of the $\gamma$ energy spectrum. $N$ is the number of $\gamma$ photons emitted.

\section{MC Simulation Calculation}

\subsection{The Influence of Different Sizes on Photon Yield and Detection Efficiency}

The experiment simulated the effects of different sizes of $\mathrm{BaClBr}(\mathrm{Eu})$ scintillators and $\mathrm{NaCl}(\mathrm{Tl})$ scintillators on photon yield and source peak efficiency. Set the energy of the radioactive source to $662 \mathrm{keV}$, and the diameter and radius of the scintillation crystal to vary from $30 \mathrm{~mm}$ to $90 \mathrm{~mm}$. Table 1 shows the changes in relative photon yield and detection efficiency when the size of $\mathrm{BaClBr}(\mathrm{Eu})$ scintillators and $\mathrm{NaCl}(\mathrm{Tl})$ scintillators change. It can be seen that the detection efficiency of the scintillator detector increases as the size of the scintillator increases. Under the same size, the photon yield output of the $\mathrm{BaClBr}(\mathrm{Eu})$ scintillator is less than that of the $\mathrm{NaCl}(\mathrm{Tl})$ scintillator, and the maximum light yield difference is $6.21 \%$ and the minimum is $3.15 \%$. Under the same size, the 
Table 1. The effect of scintillator size on photon yield and relative efficiency.

\begin{tabular}{|c|c|c|c|c|c|c|c|}
\hline Radius/mm & Diameter/mm & $\begin{array}{l}\mathrm{BaClBr}(\mathrm{Eu}) \\
\text { photon yield }\end{array}$ & $\begin{array}{c}\mathrm{NAI}(\mathrm{Tl}) \\
\text { photon yield }\end{array}$ & $\begin{array}{c}\text { Difference } \\
\text { in photon } \\
\text { yield/\% }\end{array}$ & $\begin{array}{c}\mathrm{BaClBr}(\mathrm{Eu}) \\
\text { source peak } \\
\text { efficiency }\end{array}$ & $\begin{array}{l}\mathrm{NACI}(\mathrm{Tl}) \\
\text { source peak } \\
\text { efficiency }\end{array}$ & $\begin{array}{c}\text { Relative } \\
\text { efficiency/\% }\end{array}$ \\
\hline \multirow{7}{*}{30} & 30 & $4.73 \times 10^{-1}$ & $5.35 \times 10^{-1}$ & $-6.21 \%$ & $1.3 \times 10^{-10}$ & $1.1 \times 10^{-10}$ & $22.52 \%$ \\
\hline & 40 & $3.40 \times 10^{-1}$ & $4.01 \times 10^{-1}$ & $-6.18 \%$ & $1.6 \times 10^{-10}$ & $1.3 \times 10^{-10}$ & $20.05 \%$ \\
\hline & 50 & $2.40 \times 10^{-1}$ & $3.00 \times 10^{-1}$ & $-6.05 \%$ & $1.8 \times 10^{-10}$ & $1.5 \times 10^{-10}$ & $18.17 \%$ \\
\hline & 60 & $1.72 \times 10^{-1}$ & $2.24 \times 10^{-1}$ & $-5.14 \%$ & $2 \times 10^{-10}$ & $1.7 \times 10^{-10}$ & $16.23 \%$ \\
\hline & 70 & $1.22 \times 10^{-1}$ & $1.69 \times 10^{-1}$ & $-4.65 \%$ & $2.1 \times 10^{-10}$ & $1.8 \times 10^{-10}$ & $15.44 \%$ \\
\hline & 80 & $8.71 \times 10^{-2}$ & $1.26 \times 10^{-1}$ & $-3.89 \%$ & $2.1 \times 10^{-10}$ & $1.9 \times 10^{-10}$ & $14.33 \%$ \\
\hline & 90 & $6.26 \times 10^{-2}$ & $9.41 \times 10^{-2}$ & $-3.15 \%$ & $2.2 \times 10^{-10}$ & $1.9 \times 10^{-10}$ & $13.35 \%$ \\
\hline \multirow{7}{*}{40} & 30 & $4.67 \times 10^{-1}$ & $5.27 \times 10^{-1}$ & $-5.92 \%$ & $2.4 \times 10^{-10}$ & $2 \times 10^{-10}$ & $21.81 \%$ \\
\hline & 40 & $3.38 \times 10^{-1}$ & $3.98 \times 10^{-1}$ & $-6.06 \%$ & $3 \times 10^{-10}$ & $2.5 \times 10^{-10}$ & $19.45 \%$ \\
\hline & 50 & $2.42 \times 10^{-1}$ & $3.01 \times 10^{-1}$ & $-5.96 \%$ & $3.4 \times 10^{-10}$ & $2.9 \times 10^{-10}$ & $18.19 \%$ \\
\hline & 60 & $1.74 \times 10^{-1}$ & $2.26 \times 10^{-1}$ & $-5.18 \%$ & $3.7 \times 10^{-10}$ & $3.2 \times 10^{-10}$ & $16.07 \%$ \\
\hline & 70 & $1.24 \times 10^{-1}$ & $1.71 \times 10^{-1}$ & $-4.69 \%$ & $4 \times 10^{-10}$ & $3.5 \times 10^{-10}$ & $15.07 \%$ \\
\hline & 80 & $8.90 \times 10^{-2}$ & $1.29 \times 10^{-1}$ & $-3.97 \%$ & $4.1 \times 10^{-10}$ & $3.6 \times 10^{-10}$ & $13.95 \%$ \\
\hline & 90 & $6.39 \times 10^{-2}$ & $9.67 \times 10^{-2}$ & $-3.27 \%$ & $4.3 \times 10^{-10}$ & $3.8 \times 10^{-10}$ & $12.63 \%$ \\
\hline \multirow{7}{*}{50} & 30 & $4.64 \times 10^{-1}$ & $5.22 \times 10^{-1}$ & $-5.79 \%$ & $3.9 \times 10^{-10}$ & $3.2 \times 10^{-10}$ & $21.29 \%$ \\
\hline & 40 & $3.38 \times 10^{-1}$ & $3.97 \times 10^{-1}$ & $-5.89 \%$ & $4.8 \times 10^{-10}$ & $4.1 \times 10^{-10}$ & $19.25 \%$ \\
\hline & 50 & $2.44 \times 10^{-1}$ & $3.03 \times 10^{-1}$ & $-5.94 \%$ & $5.6 \times 10^{-10}$ & $4.7 \times 10^{-10}$ & $17.95 \%$ \\
\hline & 60 & $1.76 \times 10^{-1}$ & $2.30 \times 10^{-1}$ & $-5.33 \%$ & $6.1 \times 10^{-10}$ & $5.2 \times 10^{-10}$ & $15.90 \%$ \\
\hline & 70 & $1.26 \times 10^{-1}$ & $1.74 \times 10^{-1}$ & $-4.79 \%$ & $6.5 \times 10^{-10}$ & $5.6 \times 10^{-10}$ & $14.84 \%$ \\
\hline & 80 & $9.14 \times 10^{-2}$ & $1.32 \times 10^{-1}$ & $-4.03 \%$ & $6.8 \times 10^{-10}$ & $5.9 \times 10^{-10}$ & $13.62 \%$ \\
\hline & 90 & $6.58 \times 10^{-2}$ & $9.98 \times 10^{-2}$ & $-3.41 \%$ & $7 \times 10^{-10}$ & $6.2 \times 10^{-10}$ & $12.55 \%$ \\
\hline \multirow{7}{*}{60} & 30 & $4.60 \times 10^{-1}$ & $5.18 \times 10^{-1}$ & $-5.84 \%$ & $5.7 \times 10^{-10}$ & $4.6 \times 10^{-10}$ & $21.86 \%$ \\
\hline & 40 & $3.37 \times 10^{-1}$ & $3.96 \times 10^{-1}$ & $-5.94 \%$ & $7.1 \times 10^{-10}$ & $5.9 \times 10^{-10}$ & $19.40 \%$ \\
\hline & 50 & $2.44 \times 10^{-1}$ & $3.04 \times 10^{-1}$ & $-5.93 \%$ & $8.1 \times 10^{-10}$ & $6.9 \times 10^{-10}$ & $18.03 \%$ \\
\hline & 60 & $1.77 \times 10^{-1}$ & $2.31 \times 10^{-1}$ & $-5.32 \%$ & $8.9 \times 10^{-10}$ & $7.7 \times 10^{-10}$ & $16.04 \%$ \\
\hline & 70 & $1.28 \times 10^{-1}$ & $1.76 \times 10^{-1}$ & $-4.76 \%$ & $9.5 \times 10^{-10}$ & $8.3 \times 10^{-10}$ & $14.87 \%$ \\
\hline & 80 & $9.26 \times 10^{-2}$ & $1.34 \times 10^{-1}$ & $-4.10 \%$ & $1 \times 10^{-9}$ & $8.8 \times 10^{-10}$ & $13.57 \%$ \\
\hline & 90 & $6.66 \times 10^{-2}$ & $1.02 \times 10^{-1}$ & $-3.50 \%$ & $1 \times 10^{-9}$ & $9.1 \times 10^{-10}$ & $12.63 \%$ \\
\hline
\end{tabular}




\begin{tabular}{|c|c|c|c|c|c|c|c|}
\hline & 30 & $4.59 \times 10^{-1}$ & $5.17 \times 10^{-1}$ & $-5.80 \%$ & $7.7 \times 10^{-10}$ & $6.4 \times 10^{-10}$ & $21.62 \%$ \\
\hline & 40 & $3.36 \times 10^{-1}$ & $3.97 \times 10^{-1}$ & $-6.05 \%$ & $9.7 \times 10^{-10}$ & $8.1 \times 10^{-10}$ & $19.44 \%$ \\
\hline & 50 & $2.45 \times 10^{-1}$ & $3.04 \times 10^{-1}$ & $-5.91 \%$ & $1.1 \times 10^{-9}$ & $9.5 \times 10^{-10}$ & $17.83 \%$ \\
\hline \multirow[t]{7}{*}{70} & 60 & $1.78 \times 10^{-1}$ & $2.32 \times 10^{-1}$ & $-5.37 \%$ & $1.2 \times 10^{-9}$ & $1.1 \times 10^{-9}$ & $15.92 \%$ \\
\hline & 70 & $1.29 \times 10^{-1}$ & $1.77 \times 10^{-1}$ & $-4.85 \%$ & $1.3 \times 10^{-9}$ & $1.1 \times 10^{-9}$ & $14.67 \%$ \\
\hline & 80 & $9.30 \times 10^{-2}$ & $1.35 \times 10^{-1}$ & $-4.19 \%$ & $1.4 \times 10^{-9}$ & $1.2 \times 10^{-9}$ & $13.39 \%$ \\
\hline & 90 & $6.76 \times 10^{-2}$ & $1.03 \times 10^{-1}$ & $-3.57 \%$ & $1.4 \times 10^{-9}$ & $1.3 \times 10^{-9}$ & $12.38 \%$ \\
\hline & 30 & $4.57 \times 10^{-1}$ & $5.15 \times 10^{-1}$ & $-5.79 \%$ & $1 \times 10^{-9}$ & $8.3 \times 10^{-10}$ & $21.50 \%$ \\
\hline & 40 & $3.36 \times 10^{-1}$ & $3.97 \times 10^{-1}$ & $-6.05 \%$ & $1.3 \times 10^{-9}$ & $1.1 \times 10^{-9}$ & $19.43 \%$ \\
\hline & 50 & $2.46 \times 10^{-1}$ & $3.05 \times 10^{-1}$ & $-5.93 \%$ & $1.5 \times 10^{-9}$ & $1.2 \times 10^{-9}$ & $17.68 \%$ \\
\hline \multirow[t]{7}{*}{80} & 60 & $1.79 \times 10^{-1}$ & $2.33 \times 10^{-1}$ & $-5.39 \%$ & $1.6 \times 10^{-9}$ & $1.4 \times 10^{-9}$ & $15.75 \%$ \\
\hline & 70 & $1.30 \times 10^{-1}$ & $1.79 \times 10^{-1}$ & $-4.89 \%$ & $1.7 \times 10^{-9}$ & $1.5 \times 10^{-9}$ & $14.48 \%$ \\
\hline & 80 & $9.40 \times 10^{-2}$ & $1.37 \times 10^{-1}$ & $-4.25 \%$ & $1.8 \times 10^{-9}$ & $1.6 \times 10^{-9}$ & $13.21 \%$ \\
\hline & 90 & $6.78 \times 10^{-2}$ & $1.04 \times 10^{-1}$ & $-3.65 \%$ & $1.9 \times 10^{-9}$ & $1.7 \times 10^{-9}$ & $12.15 \%$ \\
\hline & 30 & $4.57 \times 10^{-1}$ & $5.15 \times 10^{-1}$ & $-5.77 \%$ & $1.3 \times 10^{-9}$ & $1 \times 10^{-9}$ & $21.18 \%$ \\
\hline & 40 & $3.36 \times 10^{-1}$ & $3.97 \times 10^{-1}$ & $-6.09 \%$ & $1.6 \times 10^{-9}$ & $1.3 \times 10^{-9}$ & $19.06 \%$ \\
\hline & 50 & $2.46 \times 10^{-1}$ & $3.06 \times 10^{-1}$ & $-5.99 \%$ & $1.8 \times 10^{-9}$ & $1.6 \times 10^{-9}$ & $17.26 \%$ \\
\hline \multirow[t]{4}{*}{90} & 60 & $1.80 \times 10^{-1}$ & $2.34 \times 10^{-1}$ & $-5.44 \%$ & $2 \times 10^{-9}$ & $1.7 \times 10^{-9}$ & $15.35 \%$ \\
\hline & 70 & $1.30 \times 10^{-1}$ & $1.80 \times 10^{-1}$ & $-4.93 \%$ & $2.2 \times 10^{-9}$ & $1.9 \times 10^{-9}$ & $14.10 \%$ \\
\hline & 80 & $9.46 \times 10^{-2}$ & $1.38 \times 10^{-1}$ & $-4.30 \%$ & $2.3 \times 10^{-9}$ & $2 \times 10^{-9}$ & $12.78 \%$ \\
\hline & 90 & $6.87 \times 10^{-2}$ & $1.05 \times 10^{-1}$ & $-3.67 \%$ & $2.3 \times 10^{-9}$ & $2.1 \times 10^{-9}$ & $11.70 \%$ \\
\hline
\end{tabular}

source peak efficiency of the $\mathrm{BaClBr}(\mathrm{Eu})$ scintillator detector is higher than that of the $\mathrm{NaCl}(\mathrm{Tl})$ scintillator detector, with the maximum relative efficiency being $22.52 \%$ and the minimum being $11.7 \%$. The $\mathrm{BaClBr}(\mathrm{Eu})$ scintillator detector has the best performance when the size is $\Phi 90 \mathrm{~mm} \times 90 \mathrm{~mm}$, the light yield difference is small, and the source peak efficiency is the highest.

\subsection{Exploring the Impact of Different Energy Levels on the Photon Yield and Detection Efficiency of the Scintillator}

The experiment simulates the influence of different ray energy on the photon yield and source peak efficiency of the $\mathrm{BaClBr}(\mathrm{Eu})$ scintillator detector, $\mathrm{NaCl}(\mathrm{Tl})$ scintillator detector and CsI(Tl) scintillator detector in size $\Phi 90 \mathrm{~mm} \times 90 \mathrm{~mm}$. Table 2 shows the changes in photon yield and detection efficiency of $\mathrm{BaClBr}(\mathrm{Eu})$ scintillators, $\mathrm{NaCl}(\mathrm{Tl})$ scintillators and $\mathrm{CsI}(\mathrm{Tl})$ scintillators with a size of $\Phi 90 \mathrm{~mm} \times 90 \mathrm{~mm}$ under different ray energy. Figure 2 and Figure 3 
Table 2. Scintillator photon yield and detection efficiency under different $\gamma$-ray energy.

\begin{tabular}{|c|c|c|c|c|c|c|c|}
\hline \multirow[b]{2}{*}{$\begin{array}{c}\gamma \text {-ray } \\
\text { energy/KeV }\end{array}$} & \multirow[b]{2}{*}{ Nuclides } & \multicolumn{2}{|c|}{$\mathrm{BaClBr}(\mathrm{Eu})$} & \multicolumn{2}{|c|}{$\mathrm{NaCl}(\mathrm{Tl})$} & \multicolumn{2}{|c|}{$\mathrm{CsI}(\mathrm{Tl})$} \\
\hline & & Photon yield & $\begin{array}{l}\text { Detection } \\
\text { efficiency }\end{array}$ & Photon yield & $\begin{array}{l}\text { Detection } \\
\text { efficiency }\end{array}$ & Photon yield & Photon yield \\
\hline 160 & ${ }^{47} \mathrm{Sc}$ & $2.55 \times 10^{-1}$ & $8.37 \times 10^{-1}$ & $2.55 \times 10^{-3}$ & $8.33 \times 10^{-1}$ & $2.52 \times 10^{-3}$ & $8.49 \times 10^{-1}$ \\
\hline 320 & ${ }^{51} \mathrm{Cr}$ & $6.60 \times 10^{-3}$ & $7.32 \times 10^{-1}$ & $1.21 \times 10^{-2}$ & $7.14 \times 10^{-1}$ & $3.76 \times 10^{-3}$ & $7.68 \times 10^{-1}$ \\
\hline 412 & ${ }^{198} \mathrm{Au}$ & $2.02 \times 10^{-2}$ & $6.70 \times 10^{-1}$ & $3.51 \times 10^{-2}$ & $6.37 \times 10^{-1}$ & $1.32 \times 10^{-2}$ & $7.12 \times 10^{-1}$ \\
\hline 478 & ${ }^{7} \mathrm{Be}$ & $3.23 \times 10^{-2}$ & $6.32 \times 10^{-1}$ & $5.50 \times 10^{-2}$ & $5.89 \times 10^{-1}$ & $2.38 \times 10^{-2}$ & $6.74 \times 10^{-1}$ \\
\hline 662 & ${ }^{137} \mathrm{Cs}$ & $6.87 \times 10^{-2}$ & $5.45 \times 10^{-1}$ & $1.05 \times 10^{-1}$ & $4.88 \times 10^{-1}$ & $5.97 \times 10^{-2}$ & $5.84 \times 10^{-1}$ \\
\hline 835 & ${ }^{54} \mathrm{Mn}$ & $9.98 \times 10^{-2}$ & $4.87 \times 10^{-1}$ & $1.43 \times 10^{-1}$ & $4.23 \times 10^{-1}$ & $9.18 \times 10^{-2}$ & $5.21 \times 10^{-1}$ \\
\hline 1332 & ${ }^{60} \mathrm{Co}$ & $1.66 \times 10^{-1}$ & $3.82 \times 10^{-1}$ & $2.17 \times 10^{-1}$ & $1.30 \times 10^{-4}$ & $1.61 \times 10^{1}$ & $4.06 \times 10^{-1}$ \\
\hline
\end{tabular}

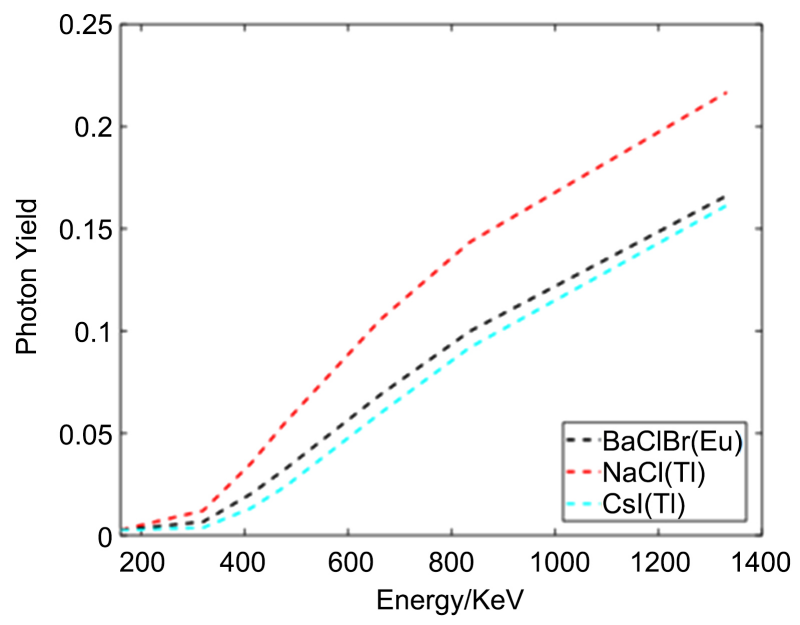

Figure 2. Photon yield of three scintillators under different $\gamma$-ray energy.

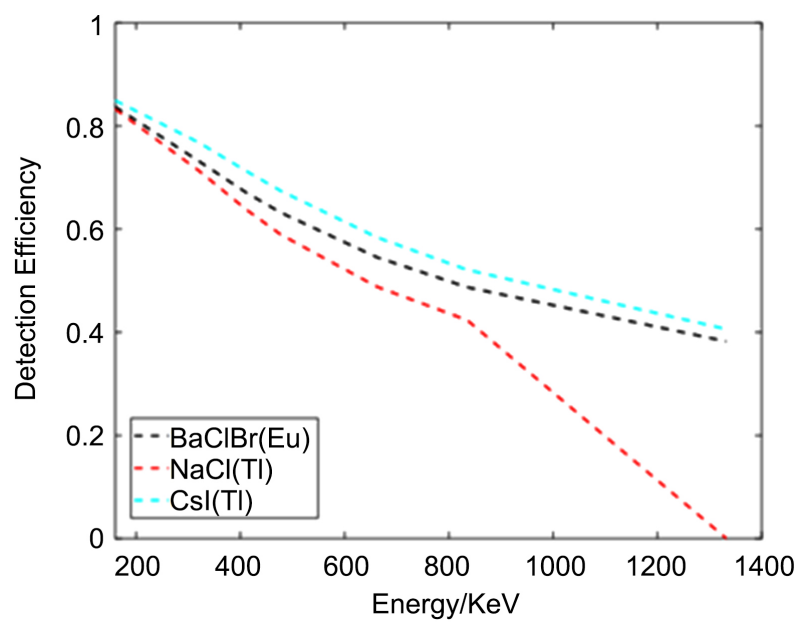

Figure 3. Detection efficiency of three kinds of scintillators under different $\gamma$-ray energy. 
show the changes in photon yield and detection efficiency of $\mathrm{BaClBr}(\mathrm{Eu})$ scintillators, $\mathrm{NaCl}(\mathrm{Tl})$ scintillators, and $\mathrm{CsI}(\mathrm{Tl})$ scintillators. It can be seen from Figure 2 that the photon yield of $\mathrm{BaClBr}(\mathrm{Eu})$ scintillator is lower than that of $\mathrm{NaCl}(\mathrm{Tl})$ scintillator, and the photon yield is higher than that of commonly used $\mathrm{CsI}(\mathrm{Tl})$ scintillator, indicating that $\mathrm{BaClBr}(\mathrm{Eu})$ scintillator has a relatively excellent photon yield. It can be seen from Figure 3 that the detection efficiency of $\mathrm{BaClBr}(\mathrm{Eu})$ scintillators and $\mathrm{NaCl}(\mathrm{Tl})$ scintillators in the low-energy range are relatively close, and the detection efficiency in the high-energy range far exceeds the latter. The detection efficiency of $\mathrm{BaClBr}(\mathrm{Eu})$ scintillator and $\mathrm{CsI}(\mathrm{Tl})$ scintillator is relatively close.

\section{Conclusion}

According to the simulation results of the MCNP5 program, the photon yield and detection efficiency of the scintillator detector are affected by the size of the scintillator. They also are affected by the magnitude of the ray energy. The detection efficiency of the scintillator detector increases as the size of the scintillator increases. The photon yield of the new $\mathrm{BaClBr}(\mathrm{Eu})$ scintillator detector is not as good as that of the traditional $\mathrm{NaCl}(\mathrm{Tl})$ scintillator, but the detection efficiency is higher than that of the $\mathrm{NaCl}(\mathrm{Tl})$ scintillator, which indicates that the new $\mathrm{BaClBr}(\mathrm{Eu})$ scintillator detector has excellent detection effectiveness. Under different $\gamma$-ray energies, the photon yields detected by the $\mathrm{BaClBr}(\mathrm{Eu})$ scintillator detector and the $\mathrm{CsI}(\mathrm{Tl})$ scintillator are relatively close, and both are lower than the $\mathrm{NaCl}(\mathrm{Tl})$ scintillator detector, indicating that its scintillation performance is good. The detection efficiency of $\mathrm{BaClBr}(\mathrm{Eu})$ scintillator detector is equivalent to $\mathrm{CsI}(\mathrm{Tl})$ scintillator detector under high and low energy rays. The detection efficiency of $\mathrm{BaClBr}(\mathrm{Eu})$ scintillator detector is compared with $\mathrm{NaCl}(\mathrm{Tl})$ scintillator detector under low energy rays. It is far surpassing $\mathrm{NaCl}(\mathrm{Tl})$ scintillator detector under high-energy rays. The simulation results of this research show that the new $\mathrm{BaClBr}(\mathrm{Eu})$ scintillator detector has good scintillation performance (energy resolution) and detection efficiency, which can be a reference for the manufacturing and selection of scintillator detection.

\section{Conflicts of Interest}

The authors declare no conflicts of interest regarding the publication of this paper.

\section{References}

[1] Su, X.B., Liu, Y.B., Liu, Y., et al. (2010) The MC Study of LaBr_3:Ce(5\%) Scintillation Detector. Nuclear Electronics and Detection Technology, 30, 1215-1219.

[2] Chen, X.Y., Zhang, Z.J. and Zhao, J.T. (2015) Scintillating Materials: A Window to Explore the World of Science. Nature Journal, 37, 165-174.

[3] Ren, G.H. and Yang, F. (2017) Research History and Status Quo of Halide Scintillation Crystals. Science China: Technical Sciences, 47, 1149-1164. https://doi.org/10.1360/N092017-00108 
[4] Boantner, L.A., Ramey, J.O., Kolopus, J.A., et al. (2005) Bridgman Growth of Large $\mathrm{SrI}_{2}: \mathrm{Eu}^{2+}$ Single Crystals. NuclInstrum Methods Phys Res SectA, 553, 550-558.

[5] van Loef, E.V., Wilson, C.M., Cherepy, N.J., et al. (2009) Crystal Growth and Scintillation Properties of Strontium Iodide Scintillators. IEEE Transactions on Nuclear Science, 56, 869-872. https://doi.org/10.1109/TNS.2009.2013947

[6] Xu, S.Y. (1996) Application of Monte Carlo Method in Experimental Nuclear Physics. Beijing, 119-126.

[7] Huang, K., Zhong, W.Y., Yan, Y.C., et al. (2018) MC Simulated BaBrI(Eu) Scintillator Light Yield and Detection Efficiency. Nuclear Electronics \& Detection Technology, 38, 865-869.

[8] Chen, B.X. and Zhang, Z. (2011) Nuclear Radiation Physics and Detection. Harbin Engineering University Press, Harbin, 274-275.

[9] Zhang, J.F. (2009) MCNP Simulation of Detection Efficiency of High Purity Germanium Detectors. Jilin University, Jilin. 